\title{
“O branco não tem panela para nos cozer”: eco popular dos movimentos pan-fricano e nacionalista no sul de Moçambique
}

Jacimara Souza Santana

\begin{abstract}
RESUMO
O racismo e a desigualdade social experimentados por povos negros na África e diáspora suscitaram a emergência de um movimento pan-africanista. Nesse sentido, suas orientações filosóficas contribuíram no desencadeamento de processos de libertação nacional em diferentes países africanos entre os anos 50 e 70. Por isso, intelectuais daquele continente desempenharam um papel significativo nesses movimentos. Enquanto pensadores e ativistas políticos demonstraram ser indissociável o ser acadêmico do militante, o ser científico do político e o ser objetivo do subjetivo. Em termos da África Austral, intelectuais como Július Nyerere e Eduardo Chivambo Mondlane entraram para a história. Tais intelectuais foram exemplos daquela combinação, cujo empenho não se deve exclusivamente às influências estrangeiras, mas também às experiências pessoais de anônimos na história, provavelmente vitais para o processo de construção destas lideranças. Estes intelectuais políticos foram, por vezes, o eco de experiências das suas comunidades de origem. Em uma relação recíproca de inspiração e conivência, atores e atrizes destas comunidades atuaram enquanto coparticipantes nos processos de transformação, de modo coletivo ou individual. Pessoas que, apesar de não terem "alisado o banco da ciência", demonstraram-se donas de uma sabedoria propiciadora de uma visão simples e profunda da vida, capaz de despertar a tomada de consciência e o encorajamento de outros no processo de transformação de uma dada realidade social. De modo que, alguns intelectuais foram e outros continuam sendo porta-vozes contemporâneos destas experiências e saberes. Neste artigo, ao invés de acompanhar a trajetória de um destes intelectuais, observando sua interação com a comunidade, demonstro expressões populares de pan-africanismo e nacionalismo no sul de Moçambique. Tais expressões, que ora superaram o status de uma reprodução do discurso dos intelectuais ora não, julgo terem contribuído com o processo de conscientização e manutenção da esperança de vitória sobre o colonialismo.
\end{abstract}

Pavras-Chave: Nacionalismo. Pan-Africanismo. População. Moçambique

\section{ABSTRACT}

Racism and social inequality experienced by black people in Africa and the diaspora caused the emergence of a panAfricanist movement. In this sense, their philosophical orientations contributed to the development of national liberation movements in different African countries from the 1950s to the 1970s. African intellectuals played a significant role in these movements, as thinkers and activists that showed the inseparability of being an academic and an activist, a scientist and a politician, objective and subjective. In Southern Africa, intellectuals such as Július Nyerere and Eduardo Chivambo Mondlane entered history. These intellectuals were examples of that combination, whose endeavors were not due solely to foreign influences, but also to the personal experiences of anonymous history, vital to the process of building these leaders. These political intellectuals were, sometimes, the echo of the experiences of their communities of origin. Regarding mutual inspiration and collusion, actors and actresses of these communities acted, thus, as coparticipantes in the process of transformation, collective or individual.These were people who, despite not having " alisado o banco da ciência " showed ownership of wisdom and deep and simple insight into life, and were able to arouse the awareness and encouragement of others in the process of transformation of the given social reality. Therefore, some intellectuals were and others continue to be spokespersons of these contemporary experiences and knowledge. In this article, rather than follow the path of one of these intellectuals, observing the interaction between this and their community, I demonstrate popular expressions of nationalism and pan-Africanism in southern Mozambique that sometimes surpassed the status of a reproduction of the discourse of intellectuals sometimes did not, which, I believe have contributed to a process of awareness and maintenance of hope in the victory over colonialism.

“O BRANCO NÃO TEM PANELA PARA NOS COZER": ECO POPULAR DOS MOVIMENTOS NACIONALISTA E PAN-AFRICANO NO SUL DE MOÇAMBIQUE

Jacimara Souza Santana ${ }^{1}$

\footnotetext{
${ }^{1}$ Bolsista CAPES-Processo no 5767-113/2012. Doutoranda do Programa de Pós-Graduação em História da Universidade Estadual de Campinas (UNICAMP) S.P. Brasil. Este texto foi apresentado na II ${ }^{\mathrm{a}}$ Conferência Internacional, "Os Intelectuais africanos face aos desafios do século XXI” Em Memória a Ruth First (1925-1982) a realizar-se em MaputoMoçambique. Complexo Pedagógico da UEM entre os dias 28 a 29 de novembro de 2012.
} 
Em geral, o pan-africanismo e a luta nacionalista no continente africano são referendados como movimentos dirigidos por um grupo de intelectuais negros formados na Europa e América, mas pouco se faz referência a coparticipação popular na sua concepção e prática. Os próprios intelectuais pan-africanos como Kwame Nkrumanh, Julius Nyerere, Jomo Kenyata, Amílcar Cabral e Eduardo Chivambo Mondlane não emergiram como tais exclusivamente fora dos contextos coletivos de suas comunidades locais. Desse modo, não creio ser um exagero afirmar que a construção dos discursos pan-africano e nacionalista, variável ao longo do tempo, foi também um produto da interação entre intelectuais e pessoas da população. O conhecimento destes intelectuais não esteve desagregado das realidades locais de suas comunidades, assim como, a luta anticolonialista e por independência nacional em Moçambique não esteve desconectada de uma rede pan-africana por independência em África.

Trata-se de uma primeira produção da pesquisa de doutorado em história que venho desenvolvendo, cuja discussão aqui apresentada possui relação com o meu tema de estudo, medicina tradicional e relações de poder. Uma parcial leitura da documentação e bibliografia sinalizou que, no contexto da luta nacional de libertação em Moçambique, década de 60, o controle exercido por autoridades coloniais aos chamados "curandeiros", também conhecidos na língua Changana por Tinyanga ou médicos tradicionais não ocupou um lugar marginal ou foi inexistente. Ao contrário do que se podia pensar, o combate do colonialismo à "subversão", na visão do governo colonial, exigia redobrar a vigilância e a investigação sobre a atuação deste grupo.

A expressão "o branco não tem panelas para nos cozer" foi colhida de um dos exemplos de eco popular do movimento nacionalista que reúno neste texto. $\mathrm{O}$ argumento apresentado pelo autor da frase durante um inquérito para explicar suas intenções ao usar esta linguagem me despertou para a observação das possíveis manobras que pessoas numa condição subordinada podiam construir no interior de um regime coercivo como foi o colonialismo em Moçambique, sobretudo em tempos de movimentação para a conquista da independência. O governo colonial tinha o poder militar, exercia o controle da circulação de informações internas e externas, exercia também a repressão das iniciativas ou de pessoas que se insurgissem contra a sua soberania e ainda, usava a estratégia de dividir para dominar. Entretanto, pessoas submetidas à colonização e distantes do núcleo político nacionalista encontraram maneiras de fazer valer interesses contrários a ordem colonial vigente, ainda que suas ações as vezes fossem, ou aparentassem ser, de ordem individual.

Isto me fez recordar a discussão sobre resistência proposta por James Scott e em parte ratificada por Allen Isaacman. Ambos sugeriram que em contextos de dominação, as populações subordinadas, sobretudo camponesas tiveram maiores possibilidade de desenvolver iniciativas disfarçadas e cotidianas de contestação, em geral com a finalidade de garantir a sua autonomia, mas que ao longo de um tempo foram propiciadoras de mudanças de uma ordem social².

${ }^{2}$ ISAACMAN, Allen F. Peasants and Rural Social Protest in Africa.In: COOPER, Frederick; ISAACMAN, Allen; MALLON, Florencia E; ROSEBERRY, William; STERN, Steve J.. Confronting Historical Paradigms Peasants, Labor, and Capitalist.World System in African and Latin America.United State of America: University of Wisconsin Press, 1993. P 
Durante os anos de luta por independência, Moçambique abrigou dois tipos de contestação: a guerra de guerrilha, que se desencadeou ao norte com abrangência para a região central e a "resistência passiva", que possibilitou manobras clandestinas em prol do movimento nacionalista, experiência comum em todas as regiões de Moçambique durante o período do domínio colonial e com grande ênfase nos tempos da conquista por independência. É no campo das ações "clandestinas" que eu me senti instigada a ensaiar a escrita deste artigo pensando as expressões do movimento nacionalista no sul. Em especial, através de pessoas que não eram reconhecidas como membros oficiais deste movimento, que não faziam parte do grupo de intelectuais ou de pessoas formadas por eles e/ou com quem mantinham uma interligação mais direta como por exemplo, os líderes que ficaram encarregados de estender a guerra de guerrilha ao sul. Antes, me ocupo das ações e reações de líderes populares neste "clima" de luta por libertação. De que maneira perceberam a ideia de libertar Moçambique do colonialismo? Que linguagens utilizaram para exprimir sua compreensão do que se passava naquele momento em terras africanas?

Assim, o objetivo deste artigo é o de apresentar alguns exemplos de como este movimento foi pensado e experimentado por diferentes pessoas e grupos da população no sul de Moçambique. Tento demonstrar expressões populares de luta nacionalista ou influenciadas por ela que estavam conectadas ou não com o discurso dos intelectuais naquele momento. Julgo que tais expressões contribuíram com o processo de conscientização e manutenção da esperança de vitória sobre o colonialismo. Ainda gostaria de acrescentar que não consigo ver o movimento nacionalista dissociado do movimento pan-africanismo, por isto os correlaciono neste texto. Especificamente, restrinjo a minha análise à província de Gaza.

\section{Movimento Pan-Africano e de Libertação Nacional na África e seus Reflexos em Moçambique}

Em geral, o movimento pan-africano e nacionalista no continente africano é referendado como um movimento dirigido por intelectuais negros formados na Europa ou América. Edward W. Blyden, Booker Y. Washisgton e W.E.Du Bois destacaram-se como protagonistas do panafricanismo em sua primeira fase. Entretanto, apesar da tendência elitista e urbana que caracterizou o nascimento deste movimento nas Américas e África, a dimensão popular não foi algo ausente de seu histórico. Marcus Garvey e posteriormente Kwame Nkrumanh conduziram o pan-africanismo para além das salas de conferências com intelectuais.

Segundo Elisa Larkin, o Garveysmo foi um dos precursores na criação de uma versão popular do movimento pan-africanista. Marcus Garvey, ao contrário da ideia integracionista pregada

205-317; SCOTT, James. Domination and the Arts of Resistance. Hidden Transcriptions. Londres: Yale University, $1^{\text {a }}$ ed.1990, Traducción de Jorge Aguilar Mora. 
inicialmente por Du Bois, defendia a independência e a autonomia política do povo negro. O seu slogan “A África para os Africanos" se tornou bastante conhecido em diferentes cantos do mundo, bem como, sua recém-nascida proposta de unidade divulgada por meio da sua Associação Universal para o Avanço do Negro com o seu jornal “Mundo Negro". Na $1^{\mathrm{a}}$ Conferência dos Povos Africanos do Mundo, realizada em Nova York, no ano de 1920, Garvey reuniu 25.000 pessoas, na qual foi aprovada uma declaração de direitos que condenavam o colonialismo e o racismo, ressaltando "o direito do negro de controlar a África”. Neste evento, também aprovaram a inclusão da história da África no ensino ${ }^{3} \mathrm{e}$ uma bandeira como símbolo da emancipação negra caracterizada pelas cores: verde, vermelho e preto que posteriormente foi associada à luta pela libertação dos povos em África4.

Entre os anos 50-60, outra figura proeminente no movimento pan-africano, cujas contribuições reafirmaram esta tendência popular, foi a de Kwame Nkhumanh. Nos anos 1945, enquanto presidente da Associação dos Estudantes Africanos, ele organizou o $5^{\circ}$ Congresso Pan-Africano em Manchester junto a outros companheiros, como por exemplo, Jomo Kenyatta. Contou também com o apoio de proeminentes do movimento, a exemplo de C.R.L. James e E. W. Du Bois. Embora tenha se tratado de um Congresso de participação mais restrita à representação das colônias britânicas, este congresso ocupou papel decisivo no direcionamento nacionalista do movimento pan-africano. Para Edem e Chanawaia, de reformista e protestante, o panafricanismo passou a ser uma ideologia nacionalista em prol da libertação das populações e do continente africano, com maior alcance entre os povos5.

A independência de Gana em 1957 desempenhou um papel significativo no apoio ao desencadeamento das independências nos demais países africanos. Kwame Nkrumanh defendeu a necessidade de assegurar a independência política para toda África, algo que deveria ser conquistado por meio da união de esforços entre os países já independentes e outros que estavam neste processo. Com esta finalidade, Nkrumanh chamou a $1^{\text {a }}$ Conferência dos Estados Independentes, para a capital do seu país, Accra, em 1958. Nesta tiveram início as discussões sobre a unidade pró-independência do continente. A criação da Organização da Unidade Africana, a OUA, em 1963 na cidade de Adis-Abeba (Etiópia), foi um dos resultados destas discussões, embora autores como Elisa Larkin afirmam que a OUA acabou atuando mais na defesa de interesses neocoloniais do que na contribuição da unidade africana ${ }^{6}$.

As discussões por unidade pró-independência no continente também tiveram reflexos em nível regional. Em termos de África Austral, vale ressaltar a criação do Pan-African Freedom Movement of East and Central Africa (PAFMECA), no ano de 1958 em Tanzania, o qual

3 A introdução do ensino de história da África no currículo do ensino brasileiro somente passou a ter validade a partir de 2003, com a lei 10.639 .

4 NASCIMENTO, Elisa Larkin. Sankofa I - A Matriz Africana No Mundo. São Paulo: Selo Negro, 2008. As cores da bandeira pan-africana, em adição da cor amarela integrou a bandeira de muitos países africanos após a independência. A bandeira de Moçambique é um exemplo destes. No Brasil, estas cores se constituíram em um símbolo de identificação dos militantes de Organizações do Movimento Negro na luta contra o racismo em conexão com a ideia de "Mãe África". Esta última expressão utilizada não no sentido de retorno, mas da manutenção de parentesco de origem dos afrobrasileiros.

5 EDEM, Kodjo; CHANAIWA, David. Pan-Africanismo e Libertação. In: MAZRUI, Ali A.; WONDJI Christophe (Eds.)

História Geral da África: África desde 1935. Brasília: UNESCO, 2010, p. 897-924, v. VIII.

6 NASCIMENTO, Elisa Larkin. Op. cit. 
conferiu significativo apoio à luta de libertação nacional em Moçambique. O acordo de cooperação estabelecido entre os Estados-membros do movimento compreendeu o treinamento a combatentes, a oferta de formação profissional e emprego público a militantes nos países independentes, bem como, a permissão para passagem de combatentes e armamento em seus territórios. Para estimular a organização de manifestações populares e a recolha de fundos próindependência, foi instituído o dia da Jornada de Libertação da África, 25 de maio, mesmo dia da fundação da OUA7.

Em Moçambique, as discussões sobre pan-africanismo e nacionalismo também tiveram origem no meio elitista e urbano. Aurélio Rocha, em sua análise sobre nativismo e nacionalismo, mostrou como as associações e seus jornais foram espaços de promoção das ideias pan-africanas e nacionalistas desde as primeiras décadas do século XX. Tal postura, no entanto, nem sempre foi comungada por todos os líderes destas organizações já que, em geral, estas foram constituídas de assimilados ${ }^{8}$. O Grêmio Africano de Lourenço Marques, a associação mais antiga de Moçambique, conforme o autor, foi fundado em 1909 e em seu manifesto de apresentação estiveram contempladas as principais questões reivindicatórias do $1^{\circ}$ Congresso Pan-Africano ocorrido em 1912: "a terra, o capital, o trabalho, o ensino e o papel do Estado"9.

Além das associações, as igrejas africanas cumpriram um importante papel na propaganda e conscientização por uma luta anticolonialista. Independente da Igreja Católica ou Protestante europeias, africanos fundaram várias organizações religiosas frequentadas exclusivamente pela população negra africana. No sul de Moçambique, antes mesmo dos anos 1930, estas igrejas alcançaram presença relevante. E o slogan garveísta “A África para os Africanos” teve uso corrente entre seus membros. O trabalho destas igrejas incomodou o governo colonial e demais autoridades a ponto de serem vistas como uma ameaça à soberania do regime. E por isto, estas igrejas foram bastante vigiadas ${ }^{10}$.

Allen Issacaman apresentou uma visão mais cética sobre a interação entre iniciativas de resistência ao colonialismo e movimento pan-africano e nacionalista em Moçambique. Em sua análise, as manifestações populares de resistência ao colonialismo ocorreram mais nas zonas rurais e esta tiveram pouca influência ou conexão com as ideias pan-africanas e até mesmo nacionalistas. Nas insurreições de camponeses por ele identificadas, o interesse, sobretudo, dos camponeses foi o de assegurar suas autonomias, ainda que se considere que a presença das igrejas independentes fosse predominante nas áreas rurais· Isaacman sugeriu que elas não

7 EDEM, Kodjo; CHANAIWA, David. Op. cit.

${ }^{8}$ Sobre o termo assimilado, consultar PEVENNE, Marie Jeanne. João dos Santos Albasini (1876-1922) - The Contradictions of Politics and Identity in Colonial Mozambique. The Journal of African History, Cambridge, v. 37, n. 3, p. 419-464, 1996. Disponível em: <www.jstor.org-stable-182500 >. Acesso: 03 maio 2011.

9 ROCHA, Aurélio. Associativismo e Nativismo em Moçambique: Contribuição para o Estudo das origens do Nacionalismo Moçambicano. Maputo: Editores-Moçambique, 2006, p. 208-249. Elisa Larkin, em sua pesquisa sobre o movimento pan-africano nas Américas, sugere que o $1^{\circ}$ Congresso teria sido realizado em 1900 e liderado por Sylvester Wiliams e não aquele de 1912 sob a direção de Du Bois como a literatura convenciona. Se considerarmos este dado, o Grêmio Africano teria sido criado nove anos após este primeiro evento pan-africano nas Américas.

${ }^{10}$ Ibid., p. 221-223. Rocha cita um artigo de João Albasini no jornal "O Brado Africano", intitulado "O Etiopianismo", no qual, ele expõe o seu pensamento a respeito da ideia "A África para os Africanos". Albasani se mostrou muito mais a favor de uma maior integração dos africanos na sociedade "civilizada" dos colonos do que a ideia de independência política, um investimento que considerou muito precoce para os primeiros vinte e quatro anos da colonização. 
adotaram um programa anticolonialista e suas ações restringiram-se a manifestações verbais esporádicas e por vezes "apocalípticas". Casos de envolvimento das Igrejas Africanas em insurreições podiam ser considerados como uma exceção, a exemplo da Igreja Metodista que foi associada a várias atividades reconhecidas como "subversivas" por autoridades coloniais (acusada de fazer parte do Congresso Nacional Africano e responsabilizada pela eclosão da revolta em Manbone, Província de Inhambane no ano de 1952) ${ }^{11}$.

A análise de Isaacman não é diferente para as associações africanas em Moçambique e Portugal. Para o autor, os Grêmios em Moçambique não tiveram êxito no desenvolvimento de ações para resolução do "problema negro", sobretudo, por terem sido organizações elitistas a serviço de seus próprios interesses e marcadas por profundas contradições de ordem racial que acirravam divisões internas. Para ele, nem mesmo as ações promovidas por organizações mais importantes da metrópole, a Liga Africana e o Partido Negro, tiveram impactos nas colônias ${ }^{12}$.

Aqui a análise de Isaacman toma contornos bem distintos de algumas de suas produções anteriores, nas quais, ele buscou dar visibilidade as estratégias de resistência camponesa. Uma crise epistemológica? Ainda é preciso maiores investigações sobre o assunto, mas para o momento é possível considerar que Isaacman e Rocha trabalharam com o mesmo período de análise, porém com distintas áreas geográficas. Ambos centraram-se nas três primeiras décadas do século XX, porém, enquanto o estudo de Rocha foi para o ambiente urbano de Lourenço Marques, o de Isaacman direcionou-se para as zonas rurais. A partir de finais dos anos 50, com a reconfiguração internacional da luta por independência na África e o impedimento de formar partidos políticos ou outras organizações para estes fins pelo regime colonial, as associações para além de assistência mútua, atuaram como espaços clandestinos de organização política fundadas em Moçambique e colônias vizinhas ${ }^{13}$.

Tais Associações deram origem posteriormente a União Democrática de Moçambique na Rodésia do Sul (UDENAMU), a União Nacional de Moçambique Independente em Niassalândia (UNAMO) e a União Nacional de Moçambique em Tanzânia e Zanzibar (MANU). Em Lisboa, também se registrou a fundação do Movimento Anticolonialista (MAC) que integrou a luta por independência nas colônias portuguesas (1957). As igrejas independentes cumpriram também papel importante na popularização de ideais nacionalistas e pan-africanas. Estas iniciativas dentro e fora de Moçambique em prol da independência ofereceram condições para a formação da FRELIMO (1962) e dois anos depois, o início da guerra por independência no norte do país ${ }^{14}$.

11DAVIDSON, A. Basil; ISAACMAN, Allen F; PÉLESSIER, René. Política e nacionalismo nas Áfricas central e meridional - 1919-1935. In: BOAHEN, Albert Adu. História Geral da África: África sob Dominação Colonial (1885-1930). 2. ed. rev. Brasília: UNESCO, 2010, p. 786-832, v. VII. É interessante notar que a versão africana desta igreja no contexto das Américas demonstrou um efetivo comprometimento na definição de políticas pró-negro. Elisa Larkin, em sua pesquisa sobre pan-africanismo, identificou que, desde princípios do século XX, uma figura central do nacionalismo negro que teria dado contribuição decisiva à fundação da Associação Pan-Africana foi um bispo da Igreja Africana Metodista Episcopal, Henry MacNeil Turner, também cofundador da Companhia Liberiana de Êxodo. A Igreja Metodista foi uma das organizações religiosas bastante perseguidas entre os anos 50-60 pelo governo colonial.

12 Ibid., p. 821-822.

${ }^{13}$ Ao menos até as primeiras décadas do século $\mathrm{XX}$, a pesquisa de Isaacman está mais direcionada à região do Zambeze. ISAACMAN, Allen F.; ISAACMAN, Barbara. A Tradição de Resistência em Moçambique: O Vale do Zambeze, 1850-1921. Porto: Afrontamento, 1979; HEDGES, David (Org.). História de Moçambique. Moçambique no auge do colonialismo 1930-1961. 2. ed. Maputo: Livraria Universitária Universidade Eduardo Mondlane, 1999, p. 238-249, v. II. ${ }^{14}$ HEDGES, David (Org.). idem. 


\section{Eco Popular do Movimento Nacionalista e Pan-africano no Sul de Moçambique}

Em Moçambique como em outras partes do continente africano, as igrejas africanas foram reconhecidas na base de muitos movimentos por independência que emergiram no continente, por isto, o governo português se interessou pelo estudo de suas origens, atividades e extensão nas colônias. Régulos e/ou chefes africanos, assim como, Tinyanga não ocuparam papel menos importante neste sentido. No estudo da adesão das populações ao movimento por independência realizado pelos serviços de informações do governo colonial, estes líderes foram identificados como "forças sociais" influentes na população e prováveis difusores da propaganda nacionalista. Por este motivo também foram alvo de cuidadosa vigilância. A análise de alguns documentos da província de Gaza mostrou diferentes registros de iniciativas destas lideranças neste sentido.

Pode-se citar como exemplo, um caso ocorrido em $1962^{15}$ no Conselho de Chibuto, província de Gaza envolvendo um chefe de povoações, o Matxotane Jive e o régulo Jorge Ganda Jive. O régulo teria apresentado uma queixa na administração por se sentir deslegitimado na sua autoridade por este outro chefe a ele subordinado, pois, ha cinco meses se negava comparecer a banja $^{16}$ por ele convocada. Em conversa para esclarecimento de suas atitudes teria justificado "é massador receber ordens de quem vai passar chefes, régulos e brancos", também em resposta a ameaça de ser denunciado ao administrador havia declarado: "o branco não tem panela para nos cozer”. Matxotane teria sido apoiado na sua atitude de irreverência por seus parentes que também não pagavam impostos a cinco meses. Ainda acrescentou o régulo em sua reclamação que esta querela entre chefes tinha raízes no tempo do seu bisavô por motivo da legitimidade da chefia de terras daquele regulado. Mas para o administrador, as frases proferidas por Matxotane e seus parentes revelavam muito mais que uma antiga rixa entre autoridades, elas davam mostras de que "o problema do nacionalismo" que seguia agitando os povos em África estava atuante naquele distrito e merecia maiores investigações por parte da Polícia Internacional do Estado, motivo da transferência dos envolvidos para a prisão em Lourenço Marques ${ }^{17}$. Em tempos de luta contra o fim do regime colonial, frases como estas eram motivo de um processo de averiguações. Durante o inquérito sobre o caso, Matxotane Jive negou ter proferido frases como "o branco não tem panela para nos cozer", mas um de seus parentes, o Madacuane Jive assumiu a sua autoria e atendendo as exigências de explicação do que queria expressar com

\footnotetext{
151962 foi o ano em que a FRELIMO criava as Forças Populares de Libertação de Moçambique em Tanzania. ${ }_{16}$ É preciso maiores investigações sobre o assunto, mas parece que algumas palavras de origem bantu no contato com a língua do colonizador foram alteradas em sua grafia e sentido. Isto não significa dizer que elas deixaram de ser da língua bantu, contudo, parece que novos elementos lhe foram acrescidos. Não se sabe ao certo se isto se aplica ao termo Banja. No dicionário da língua Changana escrito por Bento Sitoe, encontra-se a palavra B'ándlá 1.Pátio,2.praça.3.corte.4.assembléia de anciãos.5.tropa;batalhão.6.formação política;partido político. Na documentação colonial, banja aparece com o sentido de assembleia onde autoridades locais resolviam assuntos pertinentes a vida social, política, econômica e religiosa do regulado. O termo banja também é encontrado em um dicionário da língua Nyungwe escrito por Manoel dos Anjos Martins, com o significado de casamento, lar, família, reunião familiar e reunião. Esta última língua segundo o autor, é falada ao longo do rio Zambeze, região atingida pelo processo de expansão dos povos Vanguni (A. do Sul-Mfecane) que também propiciou uma interação cultural entre os povos locais. Achei interessante identificar na língua Changana algumas poucas palavras da língua Swahili, também falada em Cabo Delgado, norte de Moçambique.

${ }_{17}$ AHM. F. Tribunais Indígenas. Conselho de Chibuto, cx. 24, 23 de outubro de 1962.
} 
aquelas palavras, disse: por mais "que fossem castigados por muito grande que fossem os castigos sempre teriam fim e não os mataria”. Vale ressaltar que este caso ocorreu um ano depois da visita de Eduardo Chivambo Mondlane em Manjacaze, província de Gaza (1961). Fontes orais indicam que nesta ocasião, Mondlane conversou com algumas pessoas, inclusive chefes, a respeito do projeto de independência para Moçambique.

Em 1962, um mês depois deste acontecimento, deu-se ao norte da colônia, a fundação das Forças Populares de Libertação de Moçambique (FPLM). É preciso maiores investigações sobre a circulação de informações nas zonas rurais e urbanas na região sul sobre o movimento de libertação nacional no continente e em Moçambique, mas parece que além das notícias serem divulgadas oralmente, havia programas de rádio e algumas pessoas possuíam este aparelho e se tornaram propagadoras destas ideias. Além disto, notícias também eram publicadas na língua local em jornais africanos, como o Nyeleti Ya Miso (Estrela da Manha) incentivado pela missão presbiteriana (suiça) ${ }^{18}$.

A atitude deste administrador refletia o estado de alerta do governo ao surgimento de qualquer sinal do "problema do nacionalismo que devastava o continente". Desde o final dos anos 1950 que as autoridades coloniais portuguesas já temiam os efeitos da determinação política por independência, por isto, notícias sobre o movimento nacionalista no continente africano, sobretudo nas colônias vizinhas passaram a gerar um volume cada vez maior de correspondências confidenciais trocadas entre o governo português e administradores. Para tentar impedir a proliferação destas ideias em Moçambique, o governo tomou várias iniciativas, entre elas: a criação de uma Polícia Internacional e de Defesa do Estado, a PIDE, responsável por identificar, investigar, controlar e punir quaisquer manifestações de adesão à luta nacionalista. Fez parte do quadro da PIDE, uma rede de informantes constituída por pessoas comuns da população nativa; houve também a criação dos Serviços de Centralização e Coordenação de Informações, o SCCI, cuja função consistiu no registro de atividades religiosas consideradas ilegais, movimentos "subversivos" ou fatos suspeitos "dentre a população nativa, nacional ou estrangeira”. A coleta destas informações deveria abranger os distritos e as províncias. A coleta de informações envolveu funcionários do governo, pessoas da população e missionários da Igreja Católica. Em entrevista, um Nyanga (singular de Tinyanga) de Alto Changane, província de Gaza comentou que as confissões se tornaram uma armadilha, quando em caso de "suspeitas", padres repassavam informações para a PIDE, conduzindo algumas pessoas a prisão antes mesmo de saírem da Igreja ${ }^{19}$.

O governo interessou-se em conhecer o papel social dos Chefes africanos, Tinyanga, líderes de Igrejas e associações por considerá-los como "forças sociais" mais influentes na população. Ademais, a adesão popular também foi vista como um fator preponderante para o sucesso do

${ }^{18}$ SILVA, Teresa Cruz e. Igrejas Protestantes e Consciência Política no Sul de Moçambique: o caso da Missão Suiça (1930-1974). Maputo: PROMEDIA, 2001.

${ }_{19}$ Arquivo do Distrito de Bilene-Macia. Correspondência do administrador J. G. T. Pereira Vila, 3 de novembro de 1959.(documentação sem classificação); Entrevista realizada com um grupo de Tinyanga da Vila de Macia (várias pessoas) por Jacimara Souza Santana. Língua Changana. Tradução para o português feita por Nyanga Secina em 19 de agosto de 2012. 
movimento nacionalista, provavelmente porque o emprego e o avanço da guerra de guerrilha dependiam de voluntários para os combates, para produzir alimentos, trabalhar na articulação política, entre outras atividades. Por isto, o SCCI elaborou questionários e estudos sobre o assunto. Um dos objetivos do governo naquele momento era reverter estas "forças sociais" em favor da sua política colonial, considerando, sobretudo, o poder de influência destes líderes nos grupos populares ${ }^{20}$.

Apesar das iniciativas, o governo colonial não conseguiu obter o controle da propaganda do movimento nacionalista. O administrador de Bilene-Macia, Fernando de Souza Ladeira, desabafou em um dos seus relatórios o quanto era dura a tarefa de policiar a difusão de ideias pro independência em seu distrito:

A propaganda efetuada na área é muito difícil de combater por ser surda e insidiosa e atingir mais o indivíduo do que o grupo. Processase geralmente por indivíduos naturais da área, vindos de Lourenço Marques (...) A propaganda que a administração tem conhecimento é toda oral e não supera a reunião de seis pessoas por grupo ${ }^{21}$.

Este caráter clandestino da propaganda identificado pelo administrador de Bilene-Macia não foi uma prática nova ou restrita a este distrito. As músicas, as danças, as poesias, as fotografias e as pinturas foram exemplos de formas disfarçadas de contestação ao regime colonial que já eram utilizados por pessoas de diferentes níveis sociais, nas cidades ou zonas urbanas. Atuar na clandestinidade foi outra maneira de lutar por independência ${ }^{22}$.

Ouvi algumas pessoas se referirem à $4^{\mathrm{a}}$ região, que compreendeu as províncias de Inhambane, Gaza e Maputo, como uma derrota porque a guerra de guerrilha não tinha alcançado esta região. Se pensarmos em outras formas de luta por independência é possível que a ideia seja outra e possa ajudar a enxergar ações individuais ou coletivas como parte ou reflexo deste movimento político no sul, aparentemente silencioso, invisível, disperso, clandestino. O serviço de informação colonial possui diferentes registros de atividades e declarações de pessoas da classe popular, por vezes líderes religiosos ou seus seguidores. Isto demonstra que para além das pessoas que tinham um contato direto com a FRELIMO - os "militantes" do movimento da $4^{\mathrm{a}}$ região - muitos destes considerados posteriormente como traidores por ceder informações mediante tortura, a luta no sul continuou.

\section{O Medo Branco da Onda Negra: a "Mau-Mau" em Tempos de "Subversão" na Província de Gaza ${ }^{23}$}

\footnotetext{
${ }^{20}$ AHM. S.E.a.III p.6n ${ }^{\circ}$ 22. ALMEIDA, José Augusto da Costa. Conquista da Adesão das Populações, 1965. ${ }^{21}$ Arquivo do Distrito de Bilene-Macia.Correspondências de Fernando de Souza Ladeira, 21 de maio de 1969. (doc. sem classificação).

${ }^{22}$ CRUZ, Tereza. A Rede Clandestina da Frelimo em Lourenço Marques. 1986. (Dissertação em História). Universidade Eduardo Mondlane, Maputo, 1986; MBOA, Matias. Memórias da luta Clandestina. Maputo: Marimbique, 2009.

${ }^{23 E s t e ~ s u b t i ́ t u l o ~ f o i ~ i n s p i r a d o ~ n o ~ t r a b a l h o ~ d e ~ C e ́ l i a ~ M a r i a ~ M a r i n h o ~ d e ~ A z e v e d o ~ i n t i t u l a d o ~ " O n d a ~ N e g r a, ~ M e d o ~ B r a n c o ", ~}$ publicado em 1987.
} 
Nas correspondências confidenciais trocadas entre o governo colonial e os administradores de províncias, no decorrer dos anos 50, nota-se um grande temor de que a guerrilha liderada pelos Kikuyu em Quênia, que ficou conhecida pelo nome de Revolta Mau Mau, chegasse até Moçambique. Este movimento de base religiosa foi muito associado ao movimento político nacionalista que se desencadeava no continente africano, aliás, visto como uma parte integrante do mesmo. Este pensamento não foi algo específico do governo colonial português, afinal foi isto que rendeu a Jomo Kenyatta passar muitos anos na cadeia, uma vez que foi acusado de líder do tal movimento. Em uma carta anônima enviada ao governo português de um amigo inglês, a "influencia Mau Mau" foi associada a propaganda escrita do movimento nacionalista que começava a se espalhar nas fronteiras da colônia portuguesa 24 .

Em outra correspondência, o Intendente do distrito de Tete pediu um parecer do governo geral à reivindicação de um grupo de europeus residentes ao norte deste distrito, Angónia. Estes europeus pediam armas e munição para a defesa no caso de uma possível expansão do movimento "Mau Mau” aquela região.

\begin{abstract}
Receosos de que a referida seita se infiltre do Niassalândia e a seguir no nosso território, manifesta a população europeia da circunscrição o desejo de possuir armas com que se possa defender-se, em caso de qualquer traiçoeiro ataque da parte dos indígenas fanáticos, sugerindo o administrador a possibilidade de distribuição de armas e munições pelos europeus que delas careçam ${ }^{25}$.
\end{abstract}

O militar Lizete Neves afirmou que todas as informações que teve acesso na fase inicial da guerra de guerrilha ao norte de Moçambique e região circunvizinhas estavam sempre vinculadas a "Mau Mau". Para Neves, a guerra anticolonialista promovida pela FRELIMO adotava os métodos guerreiros baseados em princípios culturais da referida revolta, chegando a afirmar que um dos presidentes da FRELIMO teria declarado em 1962 que além do apoio dos países comunistas em armamento, treino e ideologia para o desencadeamento da guerra por independência, Moçambique haveria de contar com outro tipo de guerrilha, a da "Mau Mau". Ao transcrever parte de uma conversa que um dos seus informantes do norte teve com um amigo de Tanzânia, tem-se:

Porque é que este ano tanta gente de tua terra vai ao Quênia comprar remédios indígenas? Vão comprar remédios para ter força para roubar? Em resposta disse o amigo. Não senhor, é para ter força para matar os brancos como fizeram os Kikuys no Quênia em 1952. Falase em Dar-Es-Salam do regresso dos Macondes portugueses para Moçambique e de como estes teriam intenções de ali praticar os actos dos Mau-Mau²6

Para Ali Mazruy, a resistência africana contra o colonialismo foi marcada por diferentes estratégias de tradições: a tradição guerreira, da revolta cristã e de guerrilha. Por tradição

\footnotetext{
24AHM.FDSNI.Conselho de Chibuto, cx 649. Carta de Amadeu Trindade-Intendente do Distrito de Manica e Sofala, Umtali-16 de novembro de 1953.

${ }_{25}^{25}$ HM.Distrito de Gaza. Conselho de Chibuto, cx 649. Carta do Intendente do Distrito de Tete, João Amadeu Trindade ao governo Geral, 7 de novembro de 1952.

${ }^{26}$ T. Tombo. SCCIM. Documento ${ }^{\circ}{ }^{1444}$. Junho de 1962.
} 
guerreira Mazruy entendeu as formas próprias nativas de combate encontradas nas culturas dos diferentes povos, como por exemplo, a "Mau Mau", movimento que se apoiou em um conjunto de valores militares e de crenças religiosas muito próprio das culturas locais, com incorporação de sua simbologia de combate. Na história do antigo Império de Gaza, a vida militar se manteve atrelada a religiosa, bem como a política. Henri Junod e Antônio Rita-Ferreira mencionaram que a preparação militar neste Império incluía a realização de cerimônias religiosas, na qual os cantos, as danças e a ingestão do remédio da guerra eram utilizados para instigar nos guerreiros a autoconfiança e a crença no poder da invencibilidade, uma prática bastante intensificada durante a guerra contra os portugueses no final do século XIX com mobilização dos melhores Tinyanga do Império com fins de garantir o sucesso. Parece que esta forma costumeira de se preparar para a guerra foi retomada na ocasião das lutas por independência nos anos 196027. Pesquisas realizadas por Terence Ranger, Kofi Asare Opoku, Basil Davidson entre outros já demonstraram o importante papel que as organizações religiosas africanas ocuparam no contexto das independências em África. No caso das Igrejas protestantes africanas, conforme eu disse anteriormente, foram consideradas como uma ameaça à soberania do regime colonial, sendo alvo de cuidadosa investigação. Estas igrejas se tornaram uma presença relevante ao sul de Moçambique e muitas delas teriam sido "importadas" por africanos que trabalhavam na África do Sul. Segundo registros do governo colonial, em toda África meridional até 1959, estas Igrejas chegavam a um total de 1.300 , elas tinham como característica comum ser lideradas e constituídas exclusivamente por negros e sua doutrina tinha como base a livre interpretação da bíblia ${ }^{28}$.

As organizações religiosas africanas foram tema de investigação por muitos anos tanto em Moçambique quanto em Angola e Guiné-Bissau. Donato Gallo em seu Saber Português analisou esta produção através dos relatórios confidenciais produzidos por administradores responsáveis por este estudo nas diferentes colônias. Em Moçambique, o administrador Afonso Ives Ferraz de Freitas dedicou cinco anos a este trabalho. Em um dos seus relatórios, chamou atenção para a frequência com que o canto Nkosi Sikelela Afrika era entoado entre os anos de 1953-1954 em diferentes ocasiões em que os africanos estavam reunidos. Notou ter acontecido isto no Centro Associativo dos Negros de Moçambique e nas Cooperativas Agrícolas de Chibuto e Manhiça

${ }_{27}$ MAZRUI, Ali A. Procurai Primeiramente o Reino Político. In: MAZRUI, Ali A.; WONDJI Christophe (Eds.). Op. cit., p. 125-150; JUNOD, Henri A. Usos e Costumes dos Bantu. Maputo: Arquivo Histórico de Moçambique. Documento 3 , 1996. Tomo I, p 398-424; RITA-FERREIRA, Antônio. Etno História e Cultura Tradicional do Grupo Anguni (Nguni).Memórias do Instituto de Investigação Científica de Moçambique. Lourenço Marques, Série C,1974, Vol II.

${ }^{28}$ RANGER, Terence O. Iniciativas e resistências africanas em face da partilha e da conquista. In: BOAHEN, Albert Adu (Coord.). História Geral da África: A África sob domínio Colonial (1880-1935). 2. ed. São Paulo: Editora Ática, 1991, p. 69-86; OPOKU, Kofi Asare. A religião na África durante a época colonial. In: BOAHEN, Albert Adu (Coord). História Geral da África: A África sob domínio Colonial (1880-1935). 2. ed. São Paulo: Editora Ática, 1991, p. 519567; DAVIDSON, A. Basil; ISAACMAN, Allen F; PÉLESSIER, René. Política e nacionalismo nas Áfricas central e meridional - 1919-1935. In: BOAHEN, Albert Adu. História Geral da África: África sob Dominação Colonial (18851930). 2. ed. rev. Brasília: UNESCO, 2010, p. 786-832, v. VII; ISAACMAN, Allen F. Peasants and Rural Social Protest in Africa.In: COOPER, Frederick; ISAACMAN, Allen; MALLON, Florencia E,; ROSEBERRY, William; STERN, Steve J.. Confronting Historical Paradigms Peaseants, Labor, and Capitalist.World System in African and Latin America.United StateofAmerica: Universityof Wisconsin Press, 1993. P 205-317; SCOTT, James. Domination and the Arts of Resistance. Hidden Transcriptins. Londres: Yale University, $1^{\mathrm{a}}$ ed.1990, Traducción de Jorge Aguilar Mora; Arquivo da Administração de Bilene-Macia; AHM. FG.Distrito de Gaza.. Concelho de Chibuto, cx. 649. 
(províncias de Maputo e Gaza). Depois veio, a saber, que se tratava de um hino africano também entoado na África do Sul e Rodésia, atual Zimbábue. Na sua interpretação, Nkosi Sikelela Afrika parecia uma canção de origem protestante e representava um elo entre as pessoas de cor negra, mas o que ele não soube até àquele dado momento é que esta canção teria sido o hino de libertação nacional lançado pelo Congresso Nacional Africano (A. Sul) em 1952, e que mais tarde se tornou um hino pan-africano. No contexto das Américas, este hino tornou-se um dos símbolos de luta contra o racismo 29 .

Em relatório do ano de 1959, os padres da Missão de São Pedro em Chissano-Gaza foram incisivos em mostrar a ameaça que a Igreja Sião União Apóstólica Cristã dos Negros da Província de Moçambique, também conhecida por Igreja Zione, representava para o domínio colonial. Os Pe. Antônio Antunes dos Santos e Celso Pinto de França realizaram um inquérito sobre as atividades desta Igreja nas escolas da missão e entre as informações colhidas, vale destacar a conversa que um dos líderes da Zion teve com o aluno Antônio Siguáque:

Um dia o chefe deles esteve lá em casa e disse: Vocês afinal rezam aos santos dos brancos, mas era bem que rezassem segundo os nossos costumes. Em Portugal, o português só tem pedras e precisam pôr estrumes nos campos para semearem as couves. Quando chegaram cá ficaram ricos por causa de nós. Qual o tempo em que eles deixarão a mama como as crianças? Desde o tempo em que os portugueses vieram nós somos escravos ${ }^{30}$, Nós não podemos ser ouvidos porque o Deus deles e os antigos deles, aqueles que eles chamam santos, não conhecem a nossa língua e a nossa raça. De modo que eles estão a enganar-nos. É preciso deixar de irdes rezar aos brancos para virdes conhecer o nosso Deus, que nos há de abrir os olhos e levantar a nossa raça e desprezar as raças dos brancos porque lá em Portugal eles morrem de fome e vem para aqui procurar comida. Eles depois de virem cá, já andam com os carros e nós não temos nada desde os tempos antigos até hoje. Afinal, nós somos como os filhos de Israel que serviram no Egito a Faraó, carregando os cestos e as pedras. Não vedes as carraças ${ }^{11}$ que se agarram ao gado e depois de estarem fartas, deixam-no? Por isso, precisas de deixar os brancos que se estão a fartar em vós....32

As palavras acima deste membro da Zion demonstram como a reinterpretação bíblica da realidade social de colonizado podia instigar atitudes de rompimento desta condição entre os crentes. A proposta deste líder da Zion era a de independência e suas palavras mostravam que ela deveria começar pela libertação das formas de pensar o colonialismo. Para Ives Ferraz de Freitas as Igrejas africanas se assemelhavam em seu caráter profético-messiânico contra o

29GALLO, Donato. Antropologia e Colonialismo. O Saber Português. Lisboa: Heptágno, 1988; AHM.Conselho Administrativo de Chibuto. Cx 649. Afonso Ives Ferraz de Freitas. Relatório Seitas Religiosas, p. 238-240. Assunto Nkosi Sekelela Africa, 10 de setembro de 1955.

$3^{\circ}$ A discussão sobre escravidão associada à imposição do trabalho forçado nas colônias portuguesas foi um assunto bastante polêmico no cenário internacional a partir de finais dos anos 1920. Mas, antes disto, o pastor metodista Kamba Simango, de Beira, ao participar do $2^{\circ}$ Congresso pan-africano já teria denunciado a condição escrava do trabalho imposto pelo regime colonial. Embora um representante da Liga Africana, em congresso anterior, tenha negado que houvesse qualquer forma de escravidão ou opressão em terras de colônia portuguesa.

${ }^{31}$ Carraca é um animal muito pequeno, uma espécie de pulga muito frequente na região em que se cria gado e quando preso à pele deste animal suga-lhe o sangue. O mesmo acontece quando uma pessoa é atingida por uma delas. 32AHM. FG. Distrito de Gaza. Administração do Conselho de Chibuto, cx 649. Vila de João Belo, 6 de maio de 1959. 
domínio colonial e na adoção do princípio a "África para os Africanos”. As igrejas Africanas no sul de Moçambique também foram responsáveis por criar um cristianismo sincrético ao integrar elementos das culturas locais a doutrina cristã, inclusive alguns pertencentes ao campo de saber dos Tinyanga. Em alguns relatórios as igrejas ziones foram indicadas como as mais próximas do universo da medicina tradicional, apesar de pregarem contra os Tinyanga 33

A questão posta aqui é a de que a religião Zion, para além de uma reação africana às igrejas cristãs, poderia ser uma espécie de versão cristã da medicina tradicional. Uma possibilidade de recusa de algumas normas não aceitáveis de sua religiosidade ancestral. Sua expansão em Moçambique consta de princípios dos anos 20 e pode ter tido uma importância significativa, uma vez que nesta colônia, perdurava o interdito da prática da medicina tradicional. A presença de Tinyanga na religião Zion é algo notável mesmo em dias atuais34.

\section{O Medo da Onda Ngungunhane: Tinyanga (“curandeiros”)}

Realizei entrevistas com grupos de Tinyanga e algumas pessoas que não faziam parte deste coletivo, moradores da província de Gaza em diferentes distritos: Xai-Xai, antiga Vila João Belo; Bilene-Macia e Chibuto. Algo que chamou muito a minha atenção em Gaza foi a frequência com que os informantes recorriam a tradição oral do antigo Império de Gaza, com destaque a figura de Ngungunhane. Até hoje, está na memória das pessoas mais velhas que não acompanharam, mas provavelmente escutaram contar por seus avós, a história deste rei tornado herói do panteão nacional da história de Moçambique. As narrações que as pessoas faziam sobre Ngungunhane pareciam estar carregadas de certo "orgulho". Em Chibuto o Nyanga Armando Madala afirmou que Tinyanga passaram a ser perseguidos pelo governo colonial porque teriam apoiado o Ngungunhane na guerra contra o domínio português. Segundo ele:

Mataram o Ngungunhane e o sucessor foi Maguiguhane depois Maguigunhane tinha relação com os "curandeiros" mataram-o e notaram que somente os sucessores podiam ser os "curandeiros" porque eles percebiam o que estava ali em redor. Então para evitar eles perseguiam os "curandeiros" para não tomarem aquela posse para não serem líderes de certas instituições que haviam [...] "curandeiros" tinham a capacidade de orientar o Ngungunhane relevante a seus trabalhos. Com isto, eles se aperceberam e queriam que os "curandeiros" andassem muito longe das tropas ou de Ngungunhane porque podiam ajudar em seus trabalhos e nós estarmos mais fortes que eles. Por isto, a cada 2 de fevereiro, os "curandeiros" de todos os distritos tem o direito de vir a casa de Ngungunhane para beber um copo de canhon [...] -Os "curandeiros" se sentiram desgraçados pelo colono, ele morreu o Ngungunhane mas teve sucessor que foi o Eduardo Mondlane. Não eram queridos [Tinyanga] não entravam e

33 AHM. FGG, cx. 2244. FREITAS, Ivens Ferraz. Seitas Religiosas em Moçambique, p. 6. ${ }^{34}$ HONWANA, Alcinda. Espíritos Vivos, Tradições Modernas. Possessões de espíritos e reintegração social pósguerra no Sul de Moçambique. Nova York: Ela por Ela, 2002. Conforme autora, a Zioni teria sua origem "na cidade americana de Zion, em Illinois, fundada em 1896 como Igreja Católica Apostólica em Zion por John Alexander Dowie. Esta Igreja chegou à África em 1904 em Johanesburg e Natal através de Daniel Bryant” e chega ao sul de Moçambique através de trabalhadores das minas em África do Sul, habitantes desta região. 
nem tinham o direito de entrar na casa de Ngungunhane porque só por sua vinda [chegada], apesar de ter morrido [Ngungunhane], só pela presença deles achavam que estava ali Ngungunhane porque todos os instrumentos que o Ngungunhane tinha eles também tinham 35 .

Em Xai-Xai, o Sr. Joaquim Arone Chiziane passou a me contar um pouco da história de Ngungunhane, o neto de Manicusse. Entre tantas coisas conversadas sobre esta figura, o Sr. Chiziane me falou que o Ngungunhane não queria o colonialismo, não queria a caça dos elefantes e os portugueses não ficaram satisfeitos com isso por que tinham interesse na venda de marfim. Ngungunhane não queria que hasteasse a bandeira portuguesa porque o rei era ele. Ngungunhane teria sido preso em Zimpeto, lugar para onde teria ido fazer cerimônia para o seu avô Manicusse, a fim de solicitar proteção durante a guerra contra os portugueses.

Em Bilene praia, o Sr. Diniz Mbendezane, o chefe do Posto Administrativo deste lugar, homem enérgico e exigente, comentou que era nativo de Manjacaze (Gaza). Lugar onde residia o rei Ngungunhane, mas na altura dos combates contra os portugueses, ele teria fugido para Chaimiti, em Zimpeto, passando por Chibuto, e teria profetizado que iria embora e que as pessoas que ficassem seriam escravizadas, porém o rei sairia de Manjacaze. Segundo Sr. Diniz, 25 anos depois, nasceu, a 3 kilômetros daquele lugar onde residia Ngungunhane, o Eduardo Chivambo Mondlane, considerado o "arquiteto da Frente de Libertação de Moçambique". Em conversa com um grupo de Tinyanga em Bilene Praia, a D. Maria, responsável do círculo do bairro, comentou:

Aqui em Gaza, o que temos muito forte na memória são os movimentos da guerra de resistência nacional, ocorrido entre Ngungunhane e o governo português. O Ngungunhane e o seu exército utilizavam medicamentos tradicionais para por nas lanças, daqueles que a um pequeno arranhão já produzia a morte. Eis que esta era uma das armas que se tinha contra soldados munidos de armas de fogo. Outra iniciativa era cercar todo o terreno com medicamentos que impediam, segundo a crença, a entrada de inimigos, ainda que este lugar não tivesse fortalezas ${ }^{36}$.

Em Alto Changane, zona situada a $25 \mathrm{~km}$ da cidade de Chibuto, na entrevista que realizei com um grupo de Tinyanga, na presença da chefe do Posto Administrativo e demais autoridades locais, ao questionar sobre a intervenção de Tinyanga durante a guerra anticolonial, a chefe manifestou-se narrando um fato que ocorreu em 1958, nas terras do régulo Chicova:

$\mathrm{Na}$ era colonial o curandeiro era perseguido porque às vezes o espírito saía e dizia a realidade. Aqui mesmo o Nyanga Jonas Beten foi perseguido porque teve espírito. Disse que, passado alguns anos, Moçambique vai ficar independente. Os portugueses hão de ir-se embora, Hão de deixar Moçambique livre. O negro vai se governar.

\footnotetext{
35 Entrevista com um grupo de Tinyanga no Distrito de Chibuto, realizada em 19 de julho de 2012.

${ }^{36}$ Entrevista com um grupo de Tinyanga de Bilene Praia realizada no dia 11 de julho de 2012. D. Maria Matias foi a intérprete da língua Changana para o português que colaborou neste diálogo. D. Maria é funcionária do Posto Administrativo de Bilene Praia.
} 
Então, foi dizer isso ao régulo que eu, tenho esta visão aqui. Pronto foi preso, porque aquele régulo trabalhava para o branco, para o português, colonizador. Então foi dizer ao patrão administrador. Olha há um preto aí que diz que os brancos hão de ir-se embora, Moçambique há de ficar livre, há de se governar. Pegaram naquele Jonas Beten e encarceraram 37.

A narrativa do caso de Jonas Beten foi confirmada pelo Nyanga José Ndau e me fez pensar no impacto daquela mensagem dos espíritos sobre a independência de Moçambique entre os demais africanos. A memória da prisão deste Nyanga sinaliza para uma possível circulação dessa mensagem. Os Tinyanga eram pessoas respeitadas, sobretudo por sua capacidade de ligar o mundo visível ao invisível. A intervenção dos espíritos na vida dos vivos não era um dado novo. Em uma correspondência de 1914, O Intendente de Negócios Indígenas e Migração alertou o administrador de Bilene-Macia para as conversas que se passavam entre os trabalhadores das minas regressados do Transvaal (Africa do Sul), alguns residentes daquele distrito:

O assumpto é muito importante como V. Exa. vê e eu devo agora acrescentar que estes boatos tem fundamento porque fatos anormais tem sido notado entre os indígenas engajados no Transvaal e recentemente idos para lá, que nos passam em Ressamo Garcia e em alguns contratados nesta cidade; assim dizem muitos indígenas que pelas povoações do interior andam profetas invisíveis anunciando coisas extraordinárias (profetas que embora invisíveis são perfeitamente ouvidos. Que o pagamento do imposto de palhota(...) o chibalo vão terminar ficando todos livres e marchando para as terras de Manicusse 38 .

O Administrador Antônio Rita Ferreira comentou que o fluxo e o refluxo de trabalhadores das minas teriam contribuído na difusão de remédios fabricados por "médicos tradicionais" da Africa do Sul em Moçambique. A propaganda dos remédios, assim como a satisfação de seus clientes era feita por meio de cartas e oralmente. Segundo informações da PIDE, este sistema estaria servindo para o recrutamento de pessoas para o movimento "subversivo". Em relatório confidencial enviado ao administrador de Gaza em 1961, a PIDE, afirmou que teria identificado mais de 200 nomes de africanos que seriam encaminhados para "uma organização política filiada ou inspirada pelo partido que levou Nkumanh ao poder" 39.

A propaganda de vacinas com ervas com finalidade de proteção dos efeitos da guerra foi outro assunto comentado nas circulares do governo. Uma circular do ano de 1961 informou que na Zambézia (região central), uma pessoa não identificada teria divulgado que haveria uma distribuição de vacinas para imunizar "todos os pretos contra balas, catanas e zagaias dos brancos", seguindo-se a isto uma guerra contra os colonos. Autoridades ressaltaram que esta propaganda coincidiu com a campanha de vacinação promovida pelo governo naquele período e que "80o trabalhadores das plantações de chã de Gorué, originários de Alto Molócuè, teriam se

37 Entrevista realizada com um grupo de Tinyanga de Alto Changane, em o6 de Julho de 2012.

${ }^{8}$ Arquivo do Distrito de Bilene-Macia. Circular Confidencial de 24 de agosto de 1914. Documentação não classificada. 39FERREIRA, A. Rita. Os Africanos de Lourenço Marques. Lourenço Marques: Instituto de Investigação Científica de Moçambique (IICM), 1967-1968. 
ausentado por três dias sem autorização". Em Gaza, no ano de 1966, O Nyanga Valentim Mucambe, morador de Vila de João Belo e recentemente chegado do Malaui foi detido por declarar-se possuidor de remédios com capacidade de proteger as pessoas que tomassem parte da guerra, podendo seus remédios "transformar um homem em árvore ou numa cobra" e fazer "que das armas em vez de balas saísse água". Além disto, mencionou que os envolvidos na guerra ao norte haviam sido treinados militarmente, mas também "sabiam fazer feitiço e como tal, nada podia lhes acontecer" 40 .

Em entrevista, alguns Tinyanga afirmaram que a vacina com ervas era ministrada em diferentes ocasiões da vida, como por exemplo, quando as pessoas tinham que emigrar para lugares distantes de sua região de morada. Por isto, não é de se estranhar que algumas pessoas solicitassem ser vacinadas antes de se deslocaram para a região dos combates no norte do país. Pode-se pensar que a busca por proteção com vacinas e amuletos entre outros recursos fazia parte da experiência religiosa daquelas pessoas, talvez isto exija retomar o antigo debate que polarizou crença e razão, sobretudo, a forma como esta primeira foi classificada no pensamento ocidental: uma superstição típica de populações pobres das zonas rurais que permanecem em um estágio "atrasado" de cultura. É possível fazer esta leitura na citação que o administrador José Alberto de Gomes Melo Branquinho sugere para demonstrar que militantes do movimento nacionalista usavam das crenças religiosas locais para popularizar a causa nacionalista e alcançar poder. Para Branquinho, Kwame Nkrumanh desenvolvia sua política com base na orientação de Ngangas. Em um dos trechos citado por ele sobre as declarações de um militante nigeriano a respeito de sua formação na Rússia, temos:

Depois do marxismo-leninismo, tive como tema de estudos as ciências ocultas. A aula de feiticeiros-doutores funcionava, aliás, unicamente para os estudantes negros [...]. Foi assim que o professor começou a sua lição: todos vocês sabem que em determinadas partes subdesenvolvidas da África o povo é altamente supersticioso e não é possível conquistá-los para objectivos políticos senão recorrendo às suas supertições. Daí a necessidade de se divulgarem os métodos que nos permitiram desencadear a revolta dos mau-mau no Quênia. Um único feiticeiro-doutor operando no meio de povos primitivos pode fazer mais propaganda do que uma dúzia de conferencistas ${ }^{4}$.

Aqui é flagrante a ideia acima já esboçada e a interpretação vai mais além. O pensamento de que as crenças supersticiosas dos pobres não os tornam capazes de ter ações políticas, ao menos que, sejam guiados por gente esclarecida que saibam dar a essa linguagem religiosa o uso mais adequado. Outro embaraço é o fato destas aulas de crenças terem sido exclusivas para estudantes negros, isto parece indicar que o fator crença era pensado como "coisa de negro". Mas o Nyanga Valentim Mucambe preso em Xai-Xai no mesmo período da produção deste estudo de Branquinho (1966) teve interpretação diferente, segundo ele, os que foram tomar

${ }^{40}$ Arquivo da Administração de Bilene-Macia. Circular confidencial, 26 de maio de 1961; Circular confidencial, 10 de maio de 1966. Documentação sem classificação.

${ }^{41}$ AHM.S.E.aIIIp $6 \mathrm{n}^{0}{ }^{21}$. BRANQUINHO, José Alberto de Melo. Prospecção das Forças Tradicionais. Manica e Sofala, 1966. 
parte nos combates ao norte tinham acesso a esta linguagem religiosa por acreditar que nada de mal lhes aconteceria. Comungar crença e política era uma antiga experiência dos Tinyanga e parece que o governo colonial também tomou consciência disto. Estas provocações remetem a discussões conceituais mais aprofundadas que pretendo retomar posteriormente com o avanço da pesquisa.

Com base na visão de que Tinyanga e suas práticas influenciavam a população e que isto tinha um grande impacto para o movimento nacionalista, o governo colonial ordenou a realização de um mapeamento da quantidade e especialidade de Tinyanga distribuídos nos regulados de toda a colônia. Entre os anos de 1960-1965, é notável o número de publicações sobre este grupo e suas ações. Além dos estudos realizados pelo SCCI já citados, administradores e antropólogos contratados se dedicaram a escrever sobre o tema. Entre os estudos identificados destaco: $\mathrm{O}$ Nhamussoro de Luis Polanach (1965); Curandice Espírita entre o Povo Ba-Tswa de Júlio Santos Peixe (1962); O Mundo Sobrenatural dos Indígenas da África Portuguesa de Jorge Dias (1961); Crenças e Práticas Mágicas em Homoíne de Antônio Rita-Ferrera (1960). Em tempos de "subversão", o interesse do governo colonial em conhecer mais "as coisas dos espíritos" pode ter se relacionado com o temor da materialização daquilo que se chamou de "revolta Mau Mau", o temor da revolta popular orientada por "forças ocultas" por meio de seus "profetas invisíveis". Em um dos estudos realizado pelo SCCI nos anos 60 nota-se uma chamada de atenção para o uso da figura de Ngungunhane por militantes como uma forma de agregar certos povos à causa da independência. É provável que estivessem se referindo a algumas populações do sul do país, especialmente alguns grupos de Gaza. O fato de Ngungunhane ter entrado para o panteão dos heróis nacionais após a independência parece ser uma evidência de que sua oposição aos portugueses na ocasião do estabelecimento do domínio colonial pode ter atuado como uma forte referência na propaganda nacionalista. Vale ressaltar que entre os povos do sul, a derrota de Ngungunhane e do Império de Gaza abrigou distintos significados no passado. Mas parece que a experiência do sofrimento durante a colonização europeia atuou como uma motivação mais ampla e determinante entre os povos para o desenvolvimento da luta por independência.

No sul, até os dias atuais, a marcha às terras de Manicusse, avô de Ngungunhane, é feita anualmente no mês de fevereiro para saudar os espíritos dos ancestrais que combateram os portugueses no passado, conforme disse o Nyanga Armando Madala, entrevistado em Chibuto, com participação de Tinyanga de todos os distritos.

\section{Considerações Finais}

Esta breve e parcial incursão sobre as fontes evidencia até o momento que: o discurso bíblico e messiânico das igrejas independentes, a tradição guerreira do Império de Gaza com suas danças, cantos e crenças mágico-religiosas e os símbolos pan-africanos de emancipação nacional, como o hino Nkosi Sikelele contribuíram para uma maior popularização das ideias nacionalistas e 
pan-africanas, uma realidade provavelmente não restrita ao sul de Moçambique. Na periferia, o discurso nacionalista adquiriu interpretações distintas daquele divulgado pelos intelectuais e adequado às realidades locais, mas de uma forma ou de outra, a determinação política por independência do colonialismo proclamada por Garvey, Nkrumanh, Eduardo Mondlane e outros ia sendo propagada.

\section{REFERENCIAS}

CRUZ, Tereza. A Rede Clandestina da Frelimo em Lourenço Marques. 1986.

(Dissertação em História). Eduardo Mondlane University, Maputo, 1986.

DAVIDSON, A. Basil; ISAACMAN, Allen F; PÉLESSIER, René. Política e nacionalismo nas Áfricas central e meridional - 1919-1935. In: BOAHEN, Albert Adu. História Geral da África: África sob Dominação Colonial (1885-1930). 2. ed. rev. Brasília: UNESCO, 2010, p. 786-832, v. VII.

EDEM, Kodjo; CHANAIWA, David. Pan-Africanismo e Libertação. In: MAZRUI, Ali A.; WONDJI Christophe (Eds.) História Geral da África: África desde 1935. Brasília: UNESCO, 2010, p. 897-924, v. VIII.

FERREIRA, A. Rita. Os Africanos de Lourenço Marques. Lourenço Marques: Instituto de Investigação Científica de Moçambique, 1967-1968.

GALLO, Donato. Antropologia e Colonialismo. O Saber Português. Lisboa: Heptágno, 1988.

HEDGES, David (Org.). História de Moçambique. Moçambique no auge do colonialismo 1930-1961. 2. ed. Maputo: Livraria Universitária Universidade Eduardo Mondlane, 1999, p. 238249, v. II.

HONWANA, Alcinda. Espíritos Vivos, Tradições Modernas. Possessões de espíritos e reintegração social pós-guerra no Sul de Moçambique. Nova York: Ela por Ela, 2002.

ISAACMAN, Allen F.; ISAACMAN, Barbara. A Tradição de Resistência em Moçambique: O Vale do Zambeze, 1850-1921. Porto: Afrontamento, 1979.

MAZRUI, Ali A. Procurai Primeiramente o Reino Político. In: MAZRUI, Ali A.; WONDJI Christophe (Eds.) História Geral da África: África desde 1935. Brasília: UNESCO, 2010, p. 125-150, v. VIII.

MBOA, Matias. Memórias da luta Clandestina. Maputo: Marimbique, 2009.

MONTEIRO, Fernando Amaro. Moçambique 1964-1974: o factor mítico-religioso como elemento de segurança ou de intervenção perante a guerra. 7. Congresso Ibérico de Estudos Africanos, Lisboa, 2010. Anais Eletronicos. 7. Congresso Ibérico de Estudos Africanos, 2010. Disponível em: <http://repositorio-

iul.iscte.pt/bitstream/10071/2424/1/CIEA7_19_MONTEIRO_Mo\%C3\%A7ambique\%201964_1 974.pdf>. Acesso: 20 jun. 2012.

NASCIMENTO, Elisa Larkin. Sankofa I - A Matriz Africana No Mundo. São Paulo: Selo Negro, 2008.

OPOKU, Kofi Asare. A religião na África durante a época colonial. In: BOAHEN, Albert Adu (Coord). História Geral da África: A África sob domínio Colonial (1880-1935). 2. ed. São Paulo: Editora Ática, 1991, p. 519-567. 
PEVENNE, Marie Jeanne. João dos Santos Albasini (1876-1922) - The Contradictions of Politics and Identity in Colonial Mozambique. The Journal of African History, Cambridge, v. 37, n. 3, p. 419-464, 1996. Disponível em: <www.jstor.org-stable-182500 >. Acesso: 03 maio 2011.

RANGER, Terence O. Iniciativas e resistências africanas em face da partilha e da conquista. In: BOAHEN, Albert Adu (Coord.). História Geral da África: A África sob domínio Colonial (1880-1935). 2. ed. São Paulo: Editora Ática, 1991, p. 69-86.

ROCHA, Aurélio. Associativismo e Nativismo em Moçambique: Contribuição para o Estudo das origens do Nacionalismo Moçambicano. Maputo: Editores-Moçambique, 2006, p. 208-249.

SOUTO, Amélia Malta de Matos Pacheco. A Administração Colonial Portuguesa em Moçambique no Período de Marcelino Caetano (1968-1974): Mecanismos e relações de poder. Dissertação do Grau de Doutoramento em História Institucional e Política, Universidade Nova de Lisboa, Faculdade de Ciências Sociais e Humanas, Instituto de História Contemporânea. Lisboa: jan, 2003.

TWUMASI, Patrick A. e WARREN, Michael.The professionalization of indigenous medicine: a comparative study of Ghana and Zambia. In: In: LAST, Murray and CHAVUNDUKA, G.L.The Professionalisation of African Medicine. Manchester University Press. International African Seminar studies, 1986. P 117-135.

WEST, Harry G. Kupilikula. O poder e o invisível em Mueda-Moçambique. Lisboa: Imprensa de Ciências Socias, 2009. Entrevista com o Secretário do Distrito de Bilene-Macia em julho de 2012.

\section{Fontes primárias e Arquivos}

Correspondências Confidenciais do Arquivo da administração do Distrito de Bilene-Macia.

Correspondências Confidenciais da Administração do Conselho de Chibuto. Fundo do Governo de Gaza do Arquivo Histórico de Moçambique.

Estudo de ALMEIDA, José Augusto da Costa. Conquista da Adesão das Populações, 1965. Arquivo Histórico de Moçambique. Sessão Especial.

Estudo de BRANQUINHO, José Alberto de Melo. Prospecção das Forças Tradicionais. Manica e Sofala, 1966.

Relatório Seitas religiosas de Afonso Ives Ferraz de Freitas. Assunto Nkosi Sekelela Africa. p. 238-240, 10 de setembro de 1955. Arquivo Histórico de Moçambique.

\section{Fontes Orais}

Entrevista com um grupo de Tinyanga no Distrito de Chibuto, realizada em 19 de julho de 2012. Acervo da autora.

Entrevista com um grupo de Tinyanga de Alto Changane, em o6 de Julho de 2012. Acervo da autora. 